\title{
HEALY CLEAN COAL PROJECT HEALY FCM TESTING AT NIRO AIR POLLUTION CONTROL PILOT FACILITY
}

\section{FINAL REPORT}

October, 1992

Cooperative Agreement No. DE-FC22-91PC90544

PREPARED FOR:

Alaska Industrial Development and Export Authority 480 West Tudor Anchorage, Alaska 


\section{ABSTRACT}

In September, 1991, pilot testing was performed at the Niro Air Pollution Control Pilot Plant in Copenhagen, Denmark in support of the Healy Clean Coal Project (HCCP), which is part of the United States Department of Energy (DOE) Clean Coal Technology III Program.

The HCCP is a proposed new coal fired power plant, located in Healy, Alaska. It consists of a TRW entrained combustion system, coupled with a limestone calciner, which operates in synergism with a Joy/Niro Spray Dryer Absorber (SDA) system equipped with a lime activation system that is designed to increase the utilization of the calcined pioduct for sulfur capture in the SDA.

The pilot tests, which were funded by the United States Department of Energy (DOE) and the Alaska Industrial Development and Export Authority (AIDEA), were conducted to investigate the characteristics of the TRW combustor/limestone calciner product, referred to as Flash Calcined Material (FCM) with respect to its ability to remove $\mathrm{SO}_{2}$ in the Joy/Niro Activated Recycle SDA system.

This report describes the pilot facility, the test objectives and methods, and the results of the tests. 


\section{EXECUTIVE SUMMMARY}

The Healy Clean Coal Project (HCCP) is a proposed new coal fired power plant, located in Healy, Alaska, which is part of the United States Department of Energy (DOE) Clean Coal Technology III Program.

The HCCP consists of a TRW Entrained Combustion System, coupled with a limestone flash calciner, which operates in synergism with a Joy/Niro Spray Dryer Absorber (SDA) system equipped with an innovative lime activation system designed to increase the reactivity of the calciner product.

TRW conducted a test burn of two Alaskan coals in support of the HCCP. The tests were conducted between March 29 and June 7, 1991 at the TRW Coal Combustion Test Facility in Cleveland, Ohio.

As part of the Cleveland tests, a five ton lot of the TRW Combustion System/Flash Calciner Material (FCM) was collected from the baghouse catch. This material was shipped to the Niro Air Pollution Control Pilot Plant, located in Copenhagen, Denmark. In September 1991, Joy/Niro conducted tests on the material to investigate its characteristics with respect to its ability to remove $\mathrm{SO}_{2}$ in a SDA system using it as the sole reagent.

\subsection{Objectives}

The objectives of the Joy/Niro pilot tests were to:

1. Determine the $\mathrm{SO}_{2}$ capture and $\mathrm{FCM}$ utilization under various operating conditions of the Joy/Niro Activated Recycle SDA System.

2. To evaluate the effectiveness of activation of the FCM by heating and abrasive grinding.

3. To verify the guaranteed limestone consumption and $\mathrm{SO}_{2}$ removal for the HCCP.

\subsection{Approach}

The test approach was to simulate the flue gas outlet conditions determined during the test run at the TRW facility in Cleveland at the Niro FGD Pilot Plant in Copenhagen, Denmark, and perform absorption tests at various operating modes for the FGD system. $\mathrm{SO}_{2}$ capture and reagent utilization was determined. A number of analytical methods were used in order to understand the individual steps in the reagent preparation and $\mathrm{SO}_{2}$ scrubbing process better. 


\subsection{Results}

The results of the Joy/Niro pilot tests were:

1. An $\mathrm{SO}_{2}$ removal efficiency of $70 \%$ can be achieved without activation of the FCM.

2. FCM utilization (reactivity) is improved by activating the material by heating or grinding.

3. $\mathrm{SO}_{2}$ removal efficiencies of $90+\%$ are expected with activation under certain conditions.

4. With activation, utilization of the FCM has been found to be better than expected with lime under the same conditions.

\subsection{Conclusions}

1. The $\mathrm{SO}_{2}$ removal guarantee of $70 \%$ will be achieved under the operating conditions specified for the HCCP.

2. Under optimum conditions, $\mathrm{SO}_{2}$ removal efficiencies of $90+\%$ are expected to orcur for the HCCP.

3. The high utilization of the FCM could be explained by the fact that some $\mathrm{SO}_{2}$ absorbing compounds, which are not $\mathrm{CaO}$, are made available (or reactive) by heating or grinding. 


\section{TEST MATERIAL}

The FCM material used for testing in Copenhagen was produced during the test work done by TRW in Cleveland, Ohio, in April and May, 1991.

The testing in Cleveland was done with coal from the Usibelli Coal Mine in Alaska and with Alaskan limestone. Because of low coal grindability and inefficient coal mill capacity, it was not possible to produce the FCM in a continuous operation mode. The FCM was instead produced in short test periods of two to three hours. Five tons of FCM was collected in separate barrels for each test and shipped to Denmark. Small samples were also taken during the tests, and sent to Copenhagen to be analyzed in the lab.

The samples were analyzed for $\mathrm{CaO}, \mathrm{CO}_{2}, \mathrm{CaSO}_{4}$, and fly ash content. The resuilts of the lab analyses and the calculated composition of the FCM from the various tests in Cleveland can be found in Table 1.

These results show that the FCM composition is very inconsistent. It was not practical to mix the FCM prior to testing in Copenhagen. Instead, the FCM was organized into groups having approximately the same content of $\mathrm{CaO}$. Then material from each group was used for a test. 


\section{DESCRIPTION OF TESTT FACILITY}

A schematic of Niro's Pilot Plant is shown in Figure 1.

The Pilot Plant consists of a SDA system, Pulse Jet Filter (PJF), feed system, gas preparation system, dry injection system and a product transport system.

The $2.2 \mathrm{~m}$ in diameter SDA chamber is equipped with a roof gas disperser, has a $60^{\circ}$ conical bottom, and is sized for a maximum flue gas flow of $2,500 \mathrm{~kg} / \mathrm{h}$ at $500^{\circ} \mathrm{C}$. The SDA is equipped with a roof gas disperser and an F10 rotary atomizer. The atomizer has a specially designed liquid distributor and is equirped with the Niro patented abrasion resistant wheel. The SDA is designed for a two-point discharge, partly from the bottom of the chamber and partly from the dust collector downstream from the spray dryer.

The PJF is a top entry baghouse with 28 bags $(7 \times 4)$ and a filter area of $36 \mathrm{~m}^{2}$. The bags are of the Ryton type. They are cleaned by pulsations of compressed air one row at a time. The cleaning can be initiated by pressure drop or by a timer. During these tests, the cleaning was initiated based on pressure drop.

The FGD Pilot Plant is designed to treat a broad range of flue gases using a pollutant injection system. Flue gas of almost any composition and temperature can be simulated. The flue gas is heated to the desired inlet temperature by a propane heater with almost no excess air. Flue gas leaving the dust collector flows through a scrubber/condenser, before it is partly recycled back through the propane heater to the spray dryer. It is possible to adjust the oxygen, carbon dioxide and the moisture contents of the gas. An injection system is provided to introduce toxic gases such as $\mathrm{SO}^{2}$ and $\mathrm{HCl}$ into the inlet duct to the spray dryer. During these tests, only $\mathrm{CO}_{2}$ was introduced into the system. The $\mathrm{SO}_{2}$ is taken from an evaporator and the flow rate is controlled by a flow controller.

The $\mathrm{SO}_{2}$ concentration in the flue gas is measured continuously by a multi-channel Hartmann \& Braun IR analyzer. Oxygen is measured by a Servomex paramagnetic analyzer. The measuring points are at the SDA inlet, the SDA outlet, and the PJF outlet.

The SDA feed system consists of holding tanks, mixing tanks, and a feed tank, all equipped with agitators. The amount of feed to the atomizer is controlled to maintain a certain SDA outlet temperature. The mixing tank is equipped with a steam jacket to heat the feed material.

The FCM is injected by means of compressed air from a silo with a screw feeder into the inlet duct to the SDA. The silo and the feeder are hung from equipment which can measure their weight. The weight loss is used for controlling the speed of the feeder and thus the amount of FCM being injected. 
The discharge from the spray dryer and the filter is pneumatically conveyed to a storage bin and then recycled and sent to disposal at controlled rates to maintain a solids content of 40 to 50 percent by the feed to the SDA atcmizer. The dry solids content is controlled by a density meter.

The pilot plant also includes a tower mill. The tower mill is a continuous or batch type stirred media mill which can be used for wet or dry fine grinding. Grinding media such as steel balls, ceramic or natural pebbles, or other material is stirred by an overhung double helix screw (or charge agitator).

Slurry to be ground may be fed to the top or to the bottom of the tower mill. A continuous upward flow is maintained by an external recycle pump. The pump is selected to provide a predetermined upward velocity allowing small feed particles to rise and large particles to fall through a discharge classifier and be fed back to the mill for additional grinding.

The action of the media is as depicted in Figure 2. Media rises within the screw flights and falls downward in the annular space between the flight tips and the inside diameters of the mill body. With steel balls as media, typical media depth is 6- to 8feet. During operation, the lower portion of the mill body is packed with media, except for a small space directly below the screw flights.

Slurry overflows from the mill body into an integral classifier or splitter. The overflow is either product or feed for subsequent classification. The underflow is recycled back to the mill. To prevent large particles from overflowing the main body, a $10 \mathrm{~mm}$ screen equipped with a vibrator is installed in the overflow.

Grinding is done by attrition/abrasion. Grinding efficiency is enhanced by the relatively high pressure between media and particles to be ground. Pre-classification and removal of product sized feed reduced overgrinding and further increases efficiency. Low noise and low heat generation further reduces energy loss.

The mill body interior is protected from wear by a grid bar system which traps media. The media itself serves as a wearing surface.

The mill can be connected to the plant for grinding of fresh diluted absorbent, for slaking, $\mathrm{CaO}$, or for grinding of the feed (product and fresh absorbent slurry). This last operating mode with FCM slurry was used for these tests. The grinding media was steel balls. Slurry temperature, the screw power consumption and the recirculation flow are displayed continuously during operating. 


\section{TECHNICAL DISCUSSION}

\subsection{Test Objectives}

The purpose of the tests was to investigate the ability of FCM collected from the TRW Slag Combustor Test facility to remove $\mathrm{SO}_{2}$ in the SDA system.

The purpose is more specifically to verify the expected limestone consu nption and $\mathrm{SO}_{2}$ removal for the HCCP.

Furthermore, the efficiencies of three FCM reactivation methods are evaluated. Those methods are: suspending the FCM in water followed by: (1) a simple agitation, (2) heating and (3) abrasive grinding.

\subsection{Test Operating Conditions}

The pilot plant was operated under the following constant operating conditions:

- Gas flow

- Inlet temperature

- Inlet $\mathrm{SO}_{2}$ concentration

- Inlet flue gas moisture

- Baghiouse pressure drop

- $\mathrm{A} / \mathrm{C}$

- Recirculation mode
$2000 \mathrm{lb} / \mathrm{h}$

$320^{\circ} \mathrm{F}$

$300 \mathrm{ppm}$, dry

13.4 vol \%

7.8 in WG

$2.3 \mathrm{ft} / \mathrm{min}$

\subsection{Test Procedure}

The pilot was started up at the pre-specified operating conditions and operated for 6-8 hours for stabilization, before starting an $\mathrm{SO}_{2}$ absorption test. The test duration was two hours, during which time operating data (temperatures, flows, pressures) were monitored and samples were taken. The $\mathrm{SO}_{2}$ concentration in the SDA inlet gas and PJF outlet gas was measured manually. Samples of FCM, feed slurry, SDA product and PJF product were collected and analyzed. 


\subsection{Results}

All of the test objectives stated in Parayraph 5.1 were accomplished. The results are as follows:

1. The SDA system $\mathrm{SO}_{2}$ removal efficiency depends on the SDA outlet temperature; lowering the SDA outlet temperature will result in higher $\mathrm{SO}_{2}$ removal efficiency.

Figure 3 depicts a plot of $\mathrm{SO}_{2}$ absorption as a function of the temperature difference between the SDA inlet (which was fixed at $320^{\circ} \mathrm{F}$ ) and the SDA outlet. It can be seen that as the temperature drop across the SDA increases (resulting in a lower SDA outlet temperature), the system $\mathrm{SO}_{2}$ removal efficiency increases.

From the data generated during the tests, it is expected that $\mathrm{SO}_{2}$ removal efficiency can vary by as much as $15 \%$ over the SDA outlet temperature range specified for the HCCP.

2. The SDA system $\mathrm{SO}_{2}$ removal efficiency will be increased by activation of the FCM through heating or abrasive grinding of the FCM slurry. Furthermore, it has been demonstrated that grinding activation will result in slightly higher $\mathrm{SO}_{2}$ absorption compared to activation by heating.

Figure 4 depicts the relationship between the $\mathrm{SO}_{2}$ removal efficiency of the SDA system and the amount of reacti ve $\mathrm{CaO}$ in the FCM entering the system. This is shown for four (4) conditions.

The lowest curve represents this relationship when no FCM activation is used. The FCM is simply mixed with water and agitated at ambient temperature.

The next higher curve shows how the SDA system is expected to perform if ordinary lime were used as the reagent instead of FCM.

The next higher curve depicts the relationship when the FCM slurry is agitated at elevated temperature for a certain period of time prior to atomization in the absorber vessel.

The top curve represents the relationship when the FCM slurry is ground in a tower mill prior to atomization. 
As can be seen from Figure 4; without activation the system performance is worse than would be expected for a typical SDA system that uses ordinary slaked lime as the absorbent. However, if the FCM is activated through heating or grinding, the system performance dramatically exceeds that of the lime bascd SDA system; this phenomenon is further explored in Result No. 3.

3. Figure 4 described the relationship between $\mathrm{SO}_{2}$ removal efficiency and the amount of $\mathrm{CaO}$ entering the SDA system. Another way to view this relationship is depicted in Figure 5 , which shows how the utilization of $\mathrm{CaO}$ relates to $\mathrm{SO}_{2}$ removal under different modes of operation of the SDA system.

We define utilization as:

\section{Mols of $\mathrm{SO}_{2}$ absorbed in process \\ Mols of $\mathrm{CaO}$ used in process}

As can be seen from Figure 5, the utilization of FCM without activation is less than that obtained for lime milk under similar conditions. Also, consistent with the results reported in Figure 4, the utilization of FCM with (either heat or grinding) activation is significantly better than that achieved with lime milk under the same conditions.

Additionally, according to the pilot test data, in certain instances the utilization is over $100 \%$ when the FCM slurry is activated by either heating or grinding. This is rather surprising in light of the following:

The reaction pertinent to sulfur capture in a lime based SDA system is shown below:

(1) $\mathrm{SO}_{2}+(1) \mathrm{Ca}(\mathrm{OH})_{2}+\frac{1 / 2 \mathrm{O}_{2}}{-\mathrm{H}_{2} \mathrm{O}}$

(1) $\mathrm{CaSO}_{4}$

Assuming that all sulfur capture in the SDA is accomplished according to the reaction and stoichiometry shown above, the maximum utilization that could be obtained from the system is $100 \%$.

The high utilization points to the presence of non- $\mathrm{CaO}$ compounds that are present. in the FCM which are capable of absorbing $\mathrm{SO}_{2}$. Presumably, these compounds are made available to the process through activation by heating or grinding.

4. Figure 6 is a plot of the expected performance of the HCCP, assuming that the FCM used for the Copenhagen pilot tests is representative of the HCCP FCM. 
As can be seen from Figure 6 , it is expected that under the specified boiler calcium to sulfur ratio (1.95) the system is expected to achieve over $70 \% \mathrm{SO}_{2}$ removal without activation. $\mathrm{SO}_{2}$ capture is excess of $90 \%$ is anticipated when the FCM is activated by heating or grinding.

\subsection{Discussion of Results}

The results of the Copenhagen pilot tests confirm that the system will be capable of at least $70 \% \mathrm{SO}_{2}$ removal under design conditions. Furthermore, it has been demonstrated that $\mathrm{SO}_{2}$ removal efficiencies of $90+\%$ are attainable under certain conditions.

Another important criteria for evaluating the performance of the SDA system is the amount of reagent necessary to achieve the required removals. To do this, we define the system Stoichriometric Ratio (SR) as follows:

$$
\begin{aligned}
& \text { Mols CaO into SDA with FCM }
\end{aligned}
$$

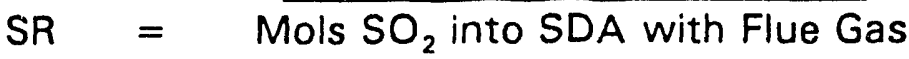

The testing at Niro's facility was under conditions similar to the conditions for the HCCP, except for the ratio of material being recirculated. The lower than expected $\mathrm{CaO}$ content in the Cleveland FCM required the amount of inerts in the system to be higher than specified for the Healy project.

In order to evaluate the test results so that they correspond to the HCCP, a SRvalue corrected for the quantity of recirculated material is calculated.

The performance coal for Healy contains chloride which will be present in the flue gas at the SDA inlet as HCL. The HCL will be absorbed in the SDA system. The pilot testing was done without $\mathrm{HCL}$ and the SR-value must be corrected for the amount of $\mathrm{CaO}$ which will react with chlorine in the coal before it can be evaluated for the conditions at Healy.

The SR-value required for a certain $\mathrm{SO}_{2}$-absorption in the HCCP SDA system is directly related to the amount of limestone injected into the boiler, and the conversion of the limestone to $\mathrm{CaO}$. The limestone conversion factor is given as:

Limestone conversation factor $=$ calcination efficiency factor $\mathrm{x}$ limestone purity. 
The calcination efficiency factor can be found by the FCM lab results and is calculated by TRW (Ref. 1). The average is found to be 0.76 for all the tests conducted by TRW to produce FCM. The limestone purity was measured to be $90 \%$ (given in the TRW-report, Ref. 1). The limestone conversion factor for the FCM used for the testing in the SDA-system was therefore .68. The value which has been used in the pre-calculation for the Healy project is 0.8 (Project Contract, Section SC-6).

The $\mathrm{Ca} / \mathrm{S}$-ratio required in the boiler to obtain a certain $\mathrm{SO}_{2}$-absorption in the SDA system can be calculated by using the limestone conversion factor. Based on testing at Niro's facility, the guaranteed $70 \%$ overall $\mathrm{SO}_{2}$ removal is easily attained, even without activation and assuming no $\mathrm{SO}_{2}$-absorption occurs in the boiler.

The Niro test results are very promising. The FCM activation process has been shown to recover some of the non- $\mathrm{CaO} \mathrm{SO}_{2}$-absorbing compounds which are apparently being encapsulated in the boiler. 


\section{TABLES}

TABLE 1: Lab Results. Samples from Cleveland Ohio 


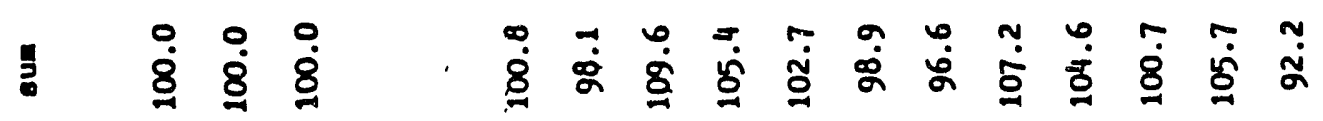

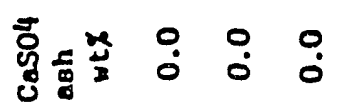

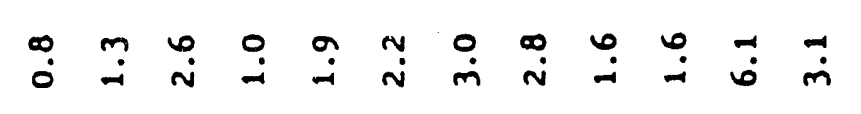

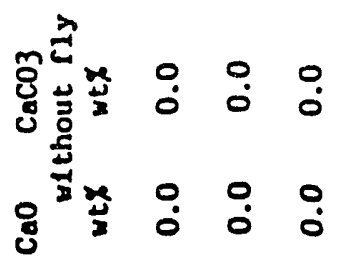

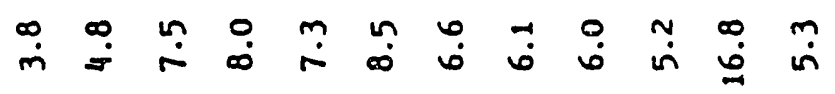

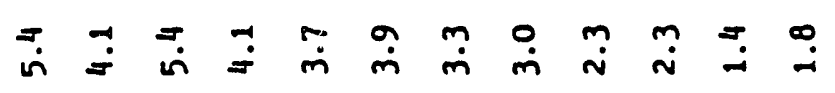

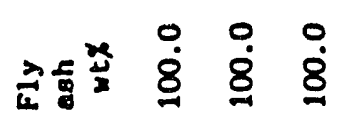

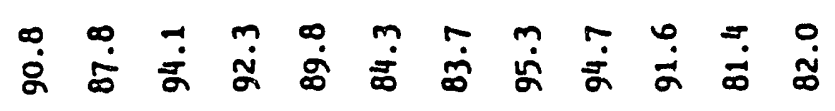

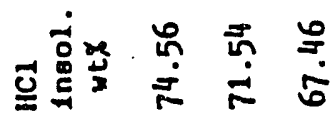

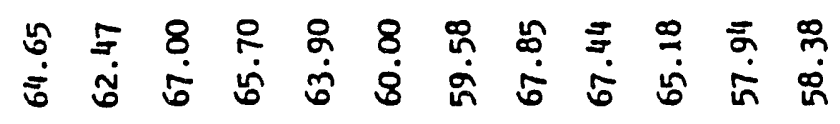

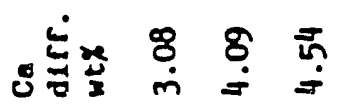

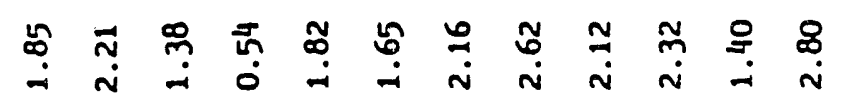

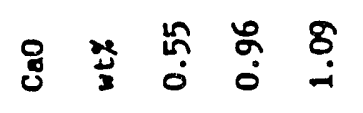

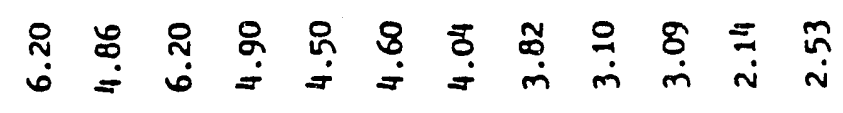

约

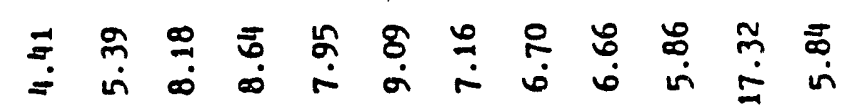

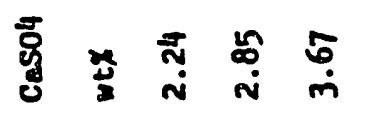

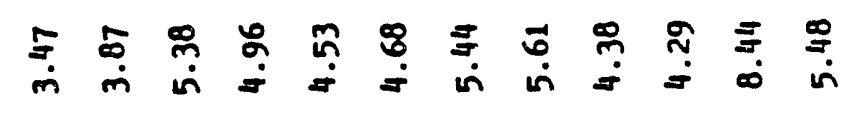

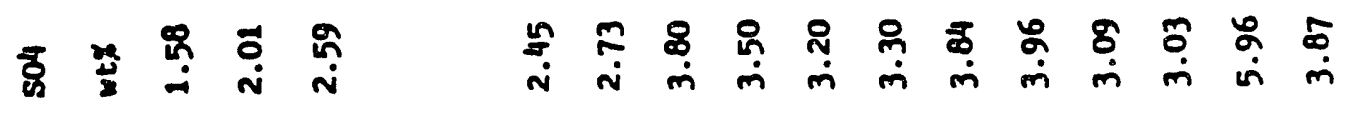

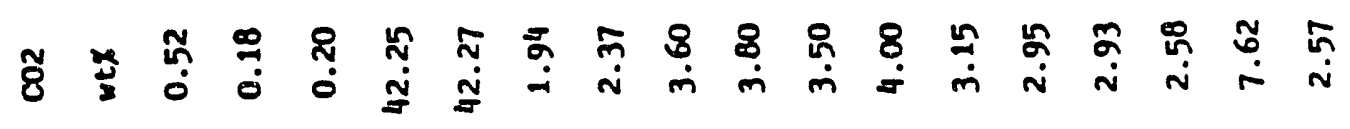

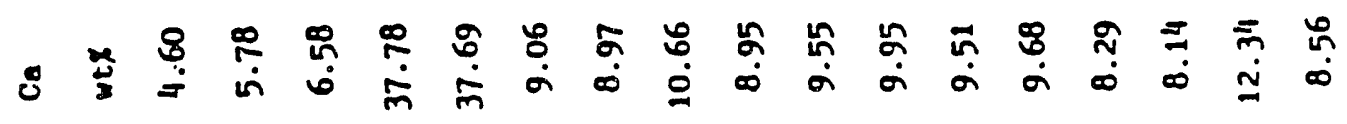

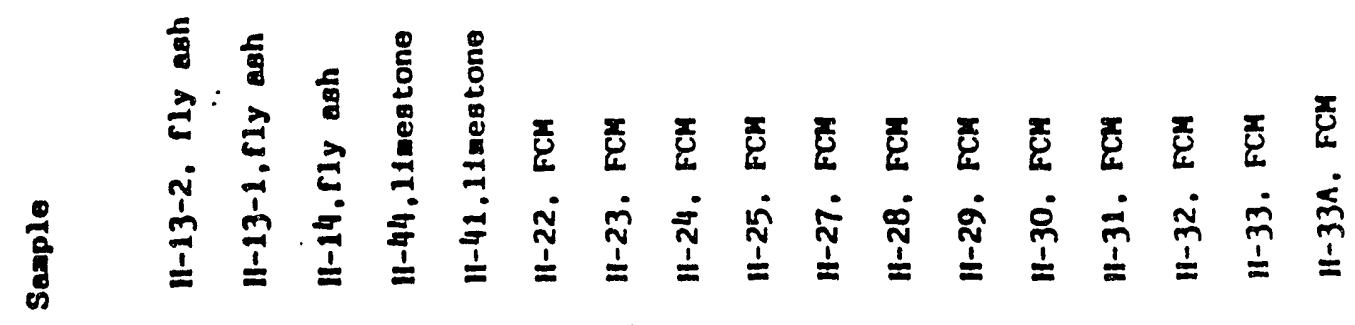




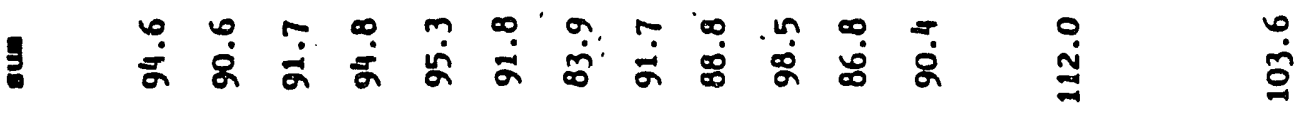
尊息

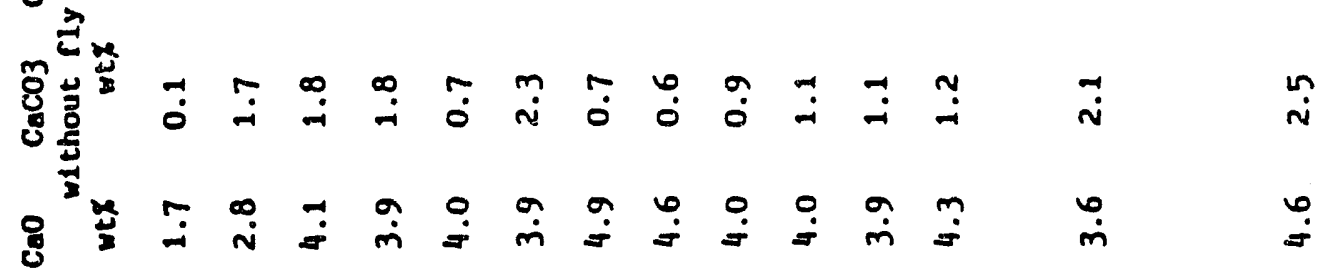

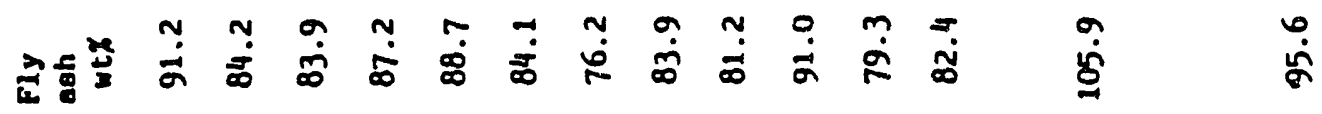

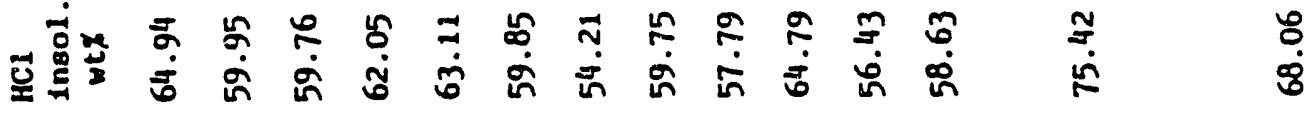

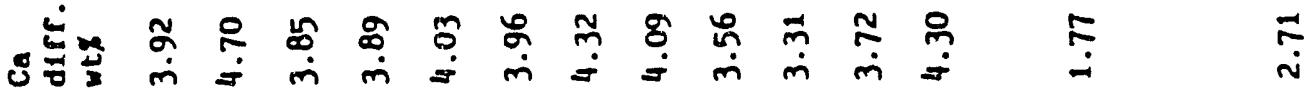
\& 思 莺 范 햄 ర̃

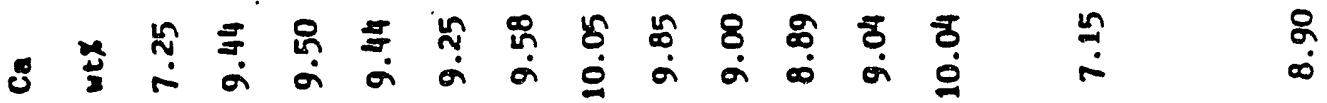

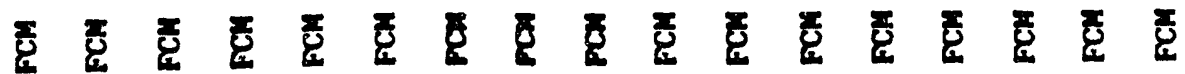

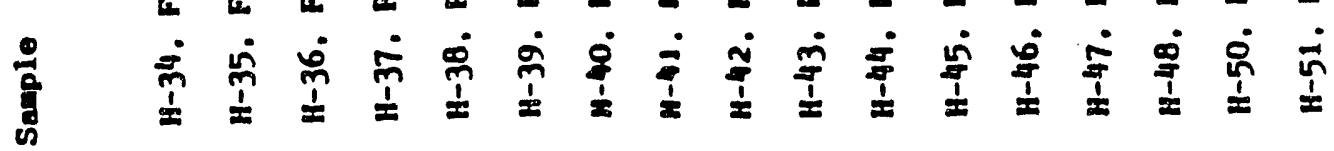




\begin{tabular}{|c|c|c|}
\hline 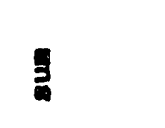 & बे & 8 \\
\hline & $\grave{0}$ & 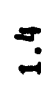 \\
\hline & $\stackrel{9}{-}$ & $\tilde{n}$ \\
\hline & $\stackrel{\circ}{=}$ & 9 \\
\hline 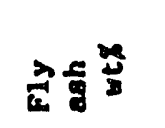 & के & 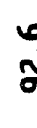 \\
\hline 可 & 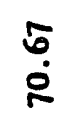 & $\begin{array}{l}a \\
\vdots \\
\vdots\end{array}$ \\
\hline 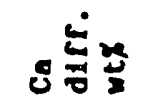 & 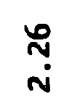 & $\bar{n}$ \\
\hline
\end{tabular}

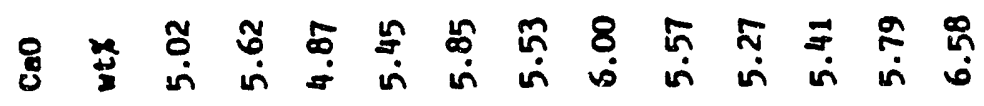

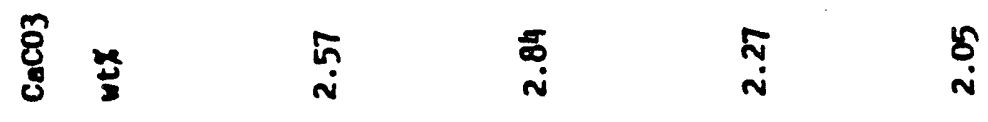

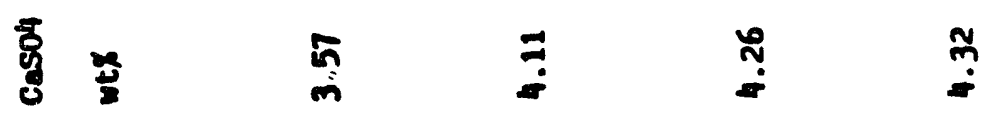

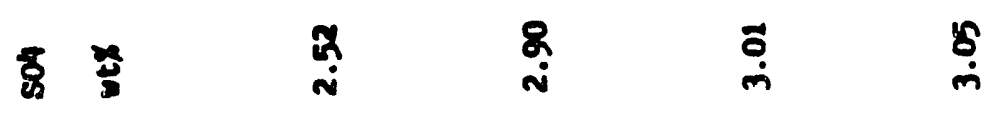

8ิ

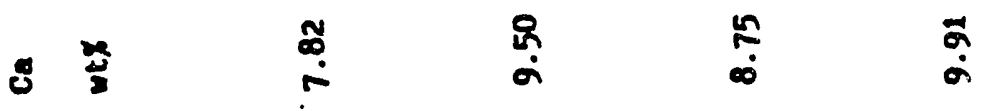

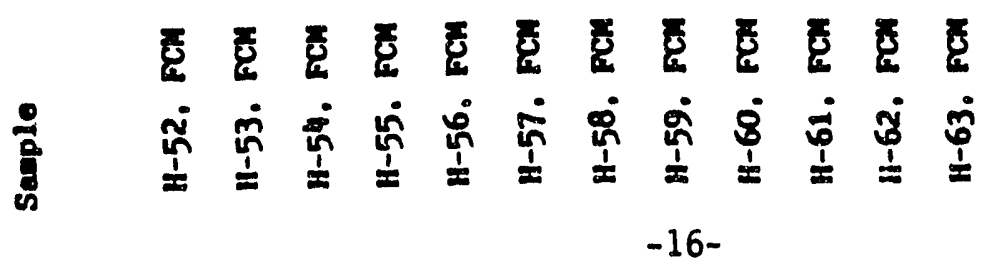




\section{FIGURES}

FIGURE 1: $\quad$ Flow Sheet, Pilot Plant

FIGURE 2: $\quad$ Tower Mill

FIGURE 3: $\quad \mathrm{SO}_{2}$ Absorption - vs - Adiabatic Saturation Approach Temperature

FIGURE 4: $\quad \mathrm{SO}_{2}$ Absorption - vs - Flyash Alkalinity

FIGURE 5: $\quad \mathrm{SO}_{2}$ Absorption - vs - CaO Utilization

FIGURE 6: $\quad \mathrm{SO}_{2}$ Absorption - vs - Boiler Stoichiometry 
Fiqure 1: Pilot plant flow sheets

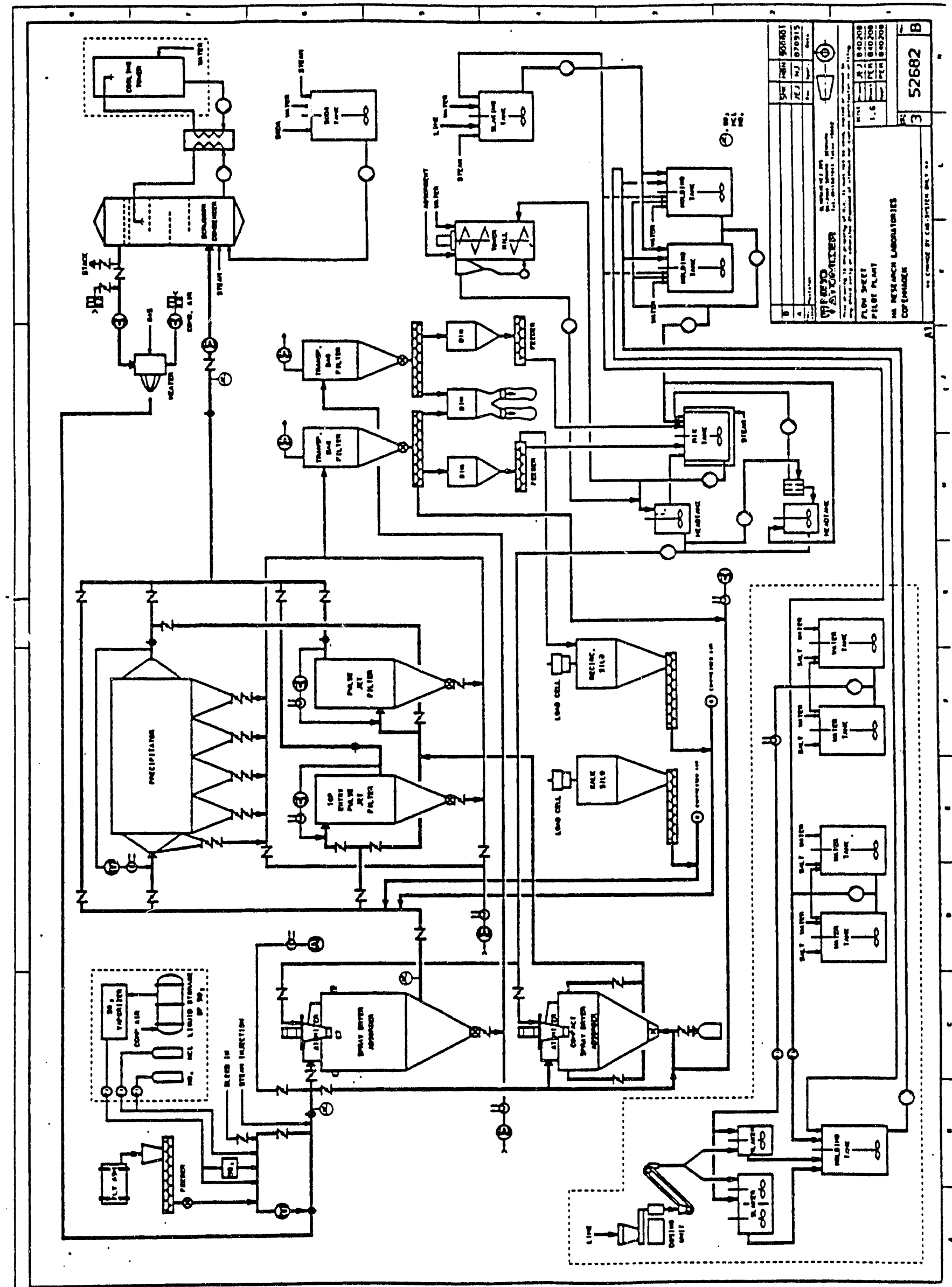


FIGURE 2

TOWER MILL

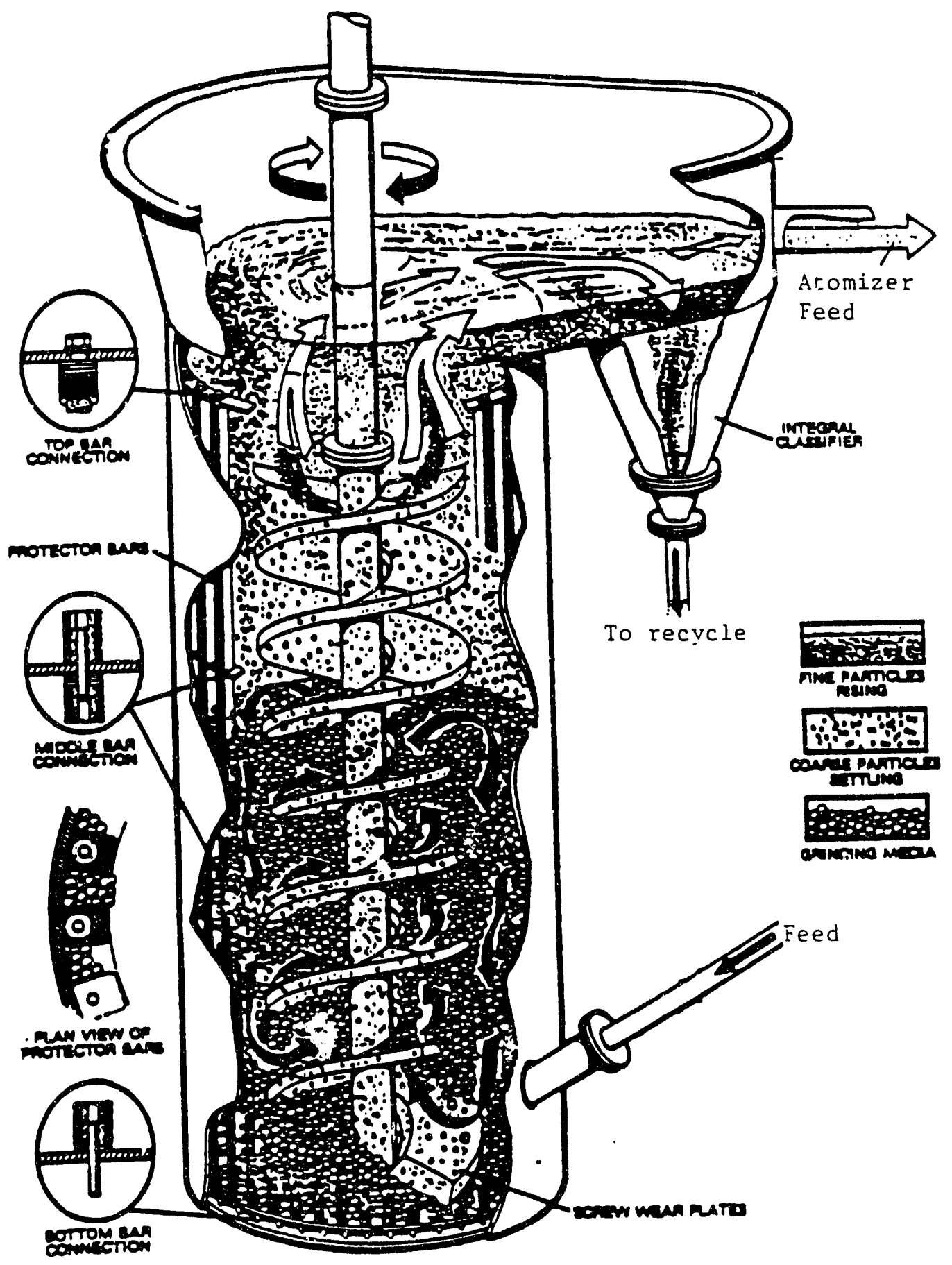




\section{PIGURE 3}

SO2 ABSORPTION - -5 - ADIABATIC SATURATION APPROACR TEMPERATURE

\section{SO2 ABSORPTION}

as function of dela $-T$

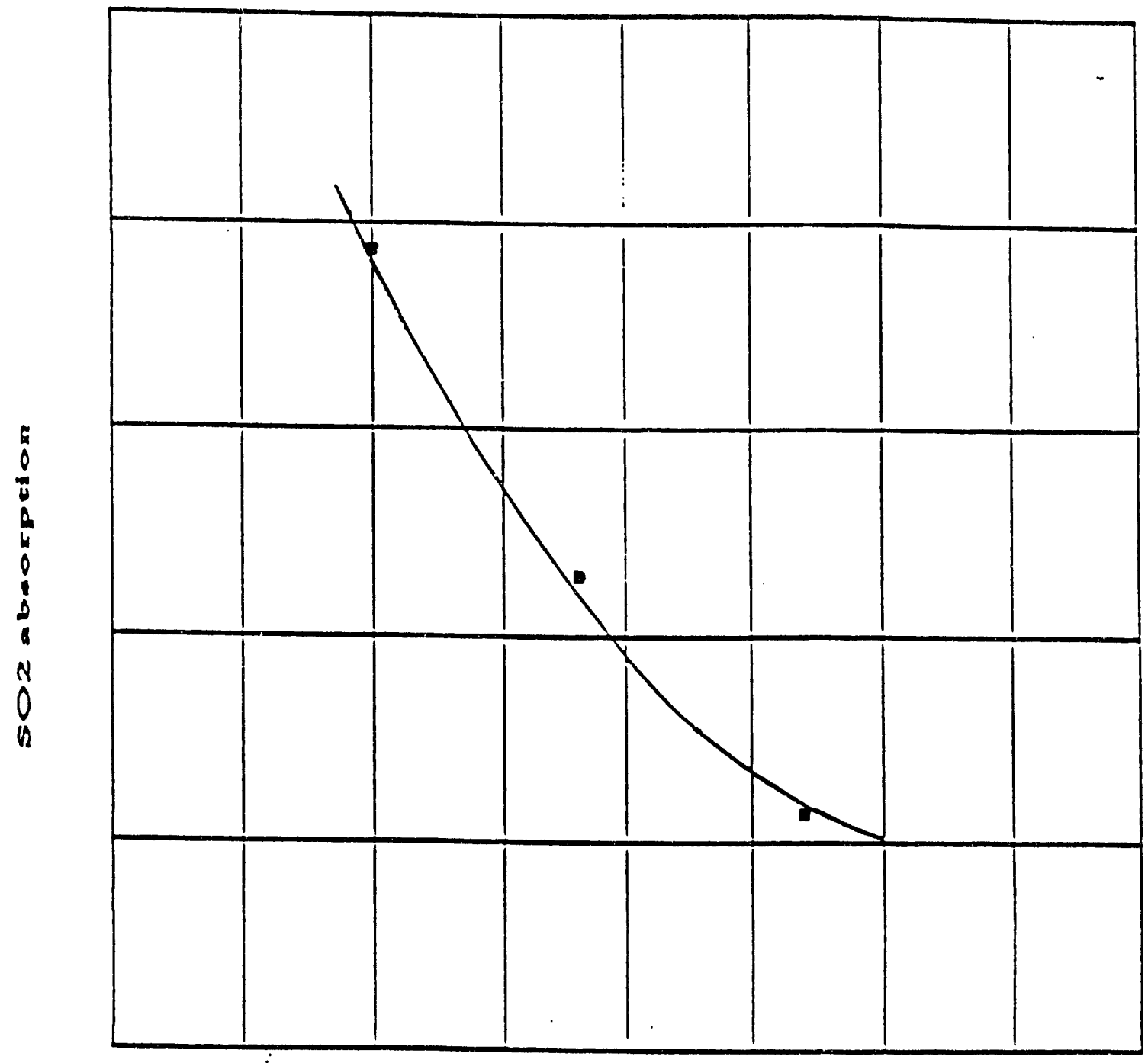

Dela $-T$

NOTE: Confidential elements of this curve have been deleter. or morified for

911030/bba puolic nisclosure. 


\section{SO2 ABSORPTION}

with differene activation methode

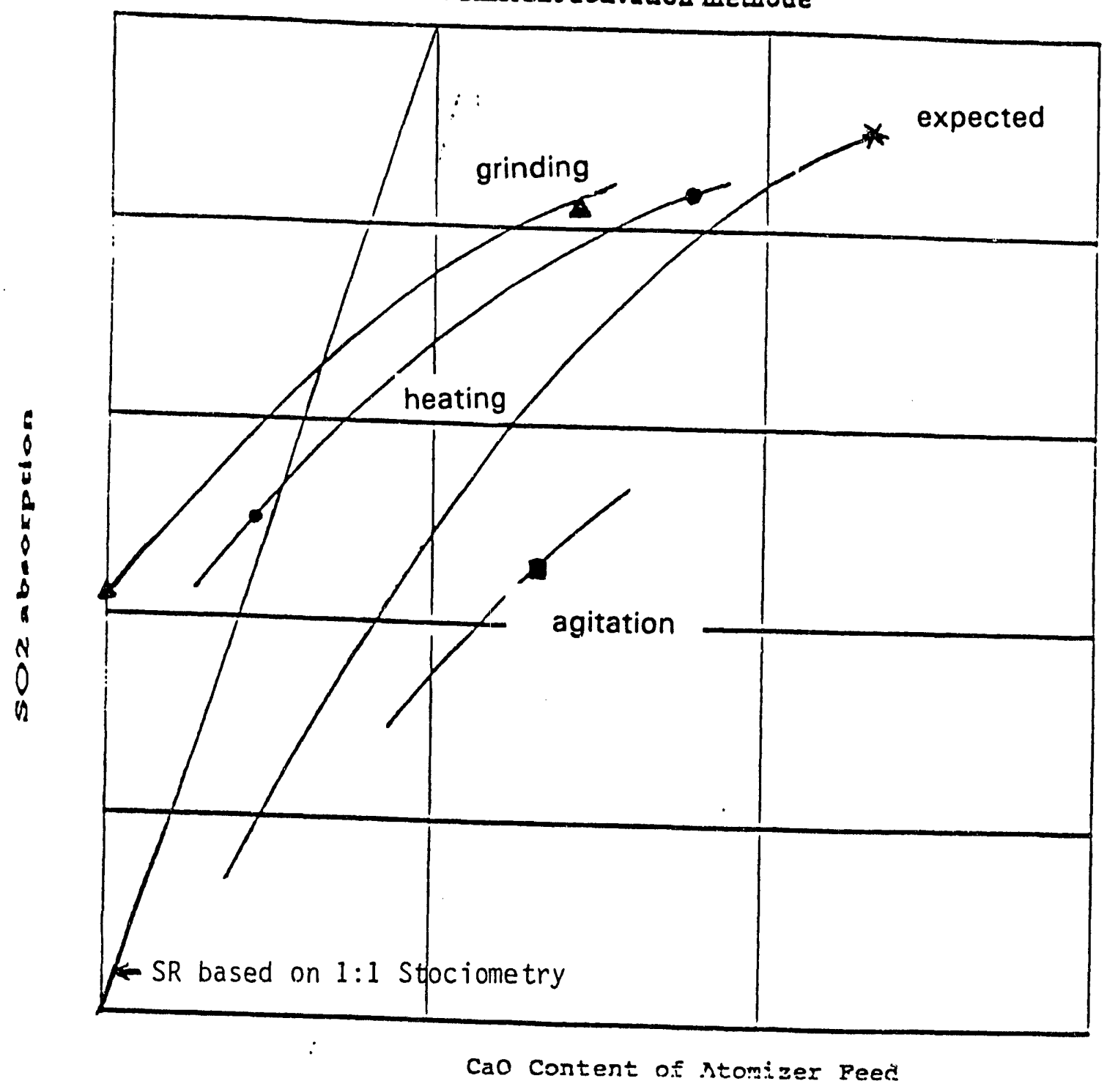

911030/hbo

agiarion bearing

grinding

expected 
FIGURE 5

302 A.3SORPTION -vs- CaO URILIZATION

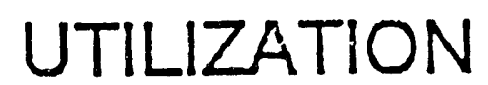

with different acrivation methode

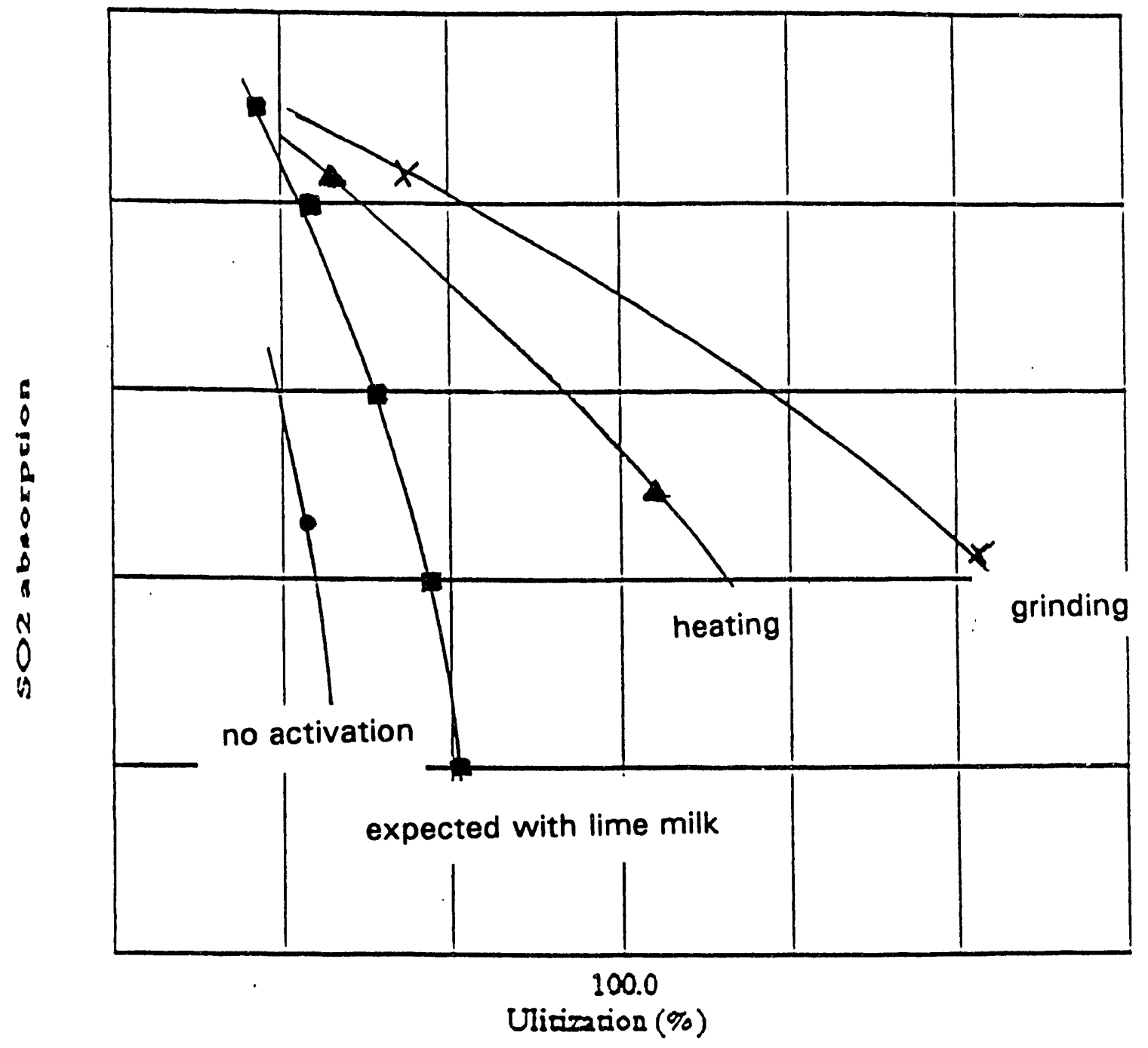

expected with lime mills

- Do zerivarion

911030/bba

$\Delta$ beating $\quad x$ grinding 


\section{FT.GURE 5}

SO2 ARSORPTION -vS- ROTLER STOTCHIOMETYOY

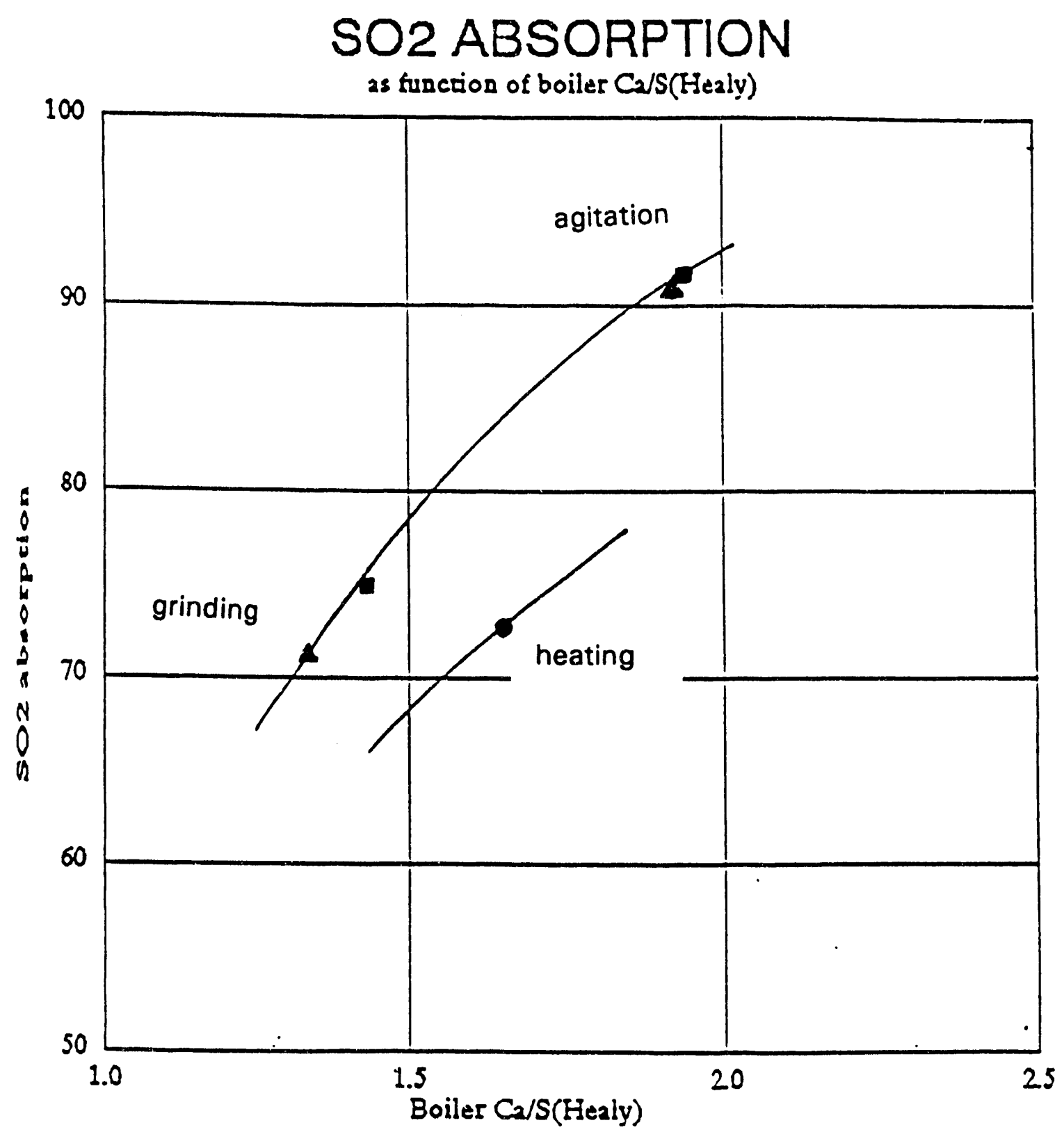

- agiezion - bearing a gnading

NoTE: Confilential elements of this curve have been deleter or motified for public iisclosure. 


\section{REFERENCES}

1. TRW Final Report "Healy Clean Coal Project, Healy Coal Firing at TRW Cleveland Test Facility," August 1991. 


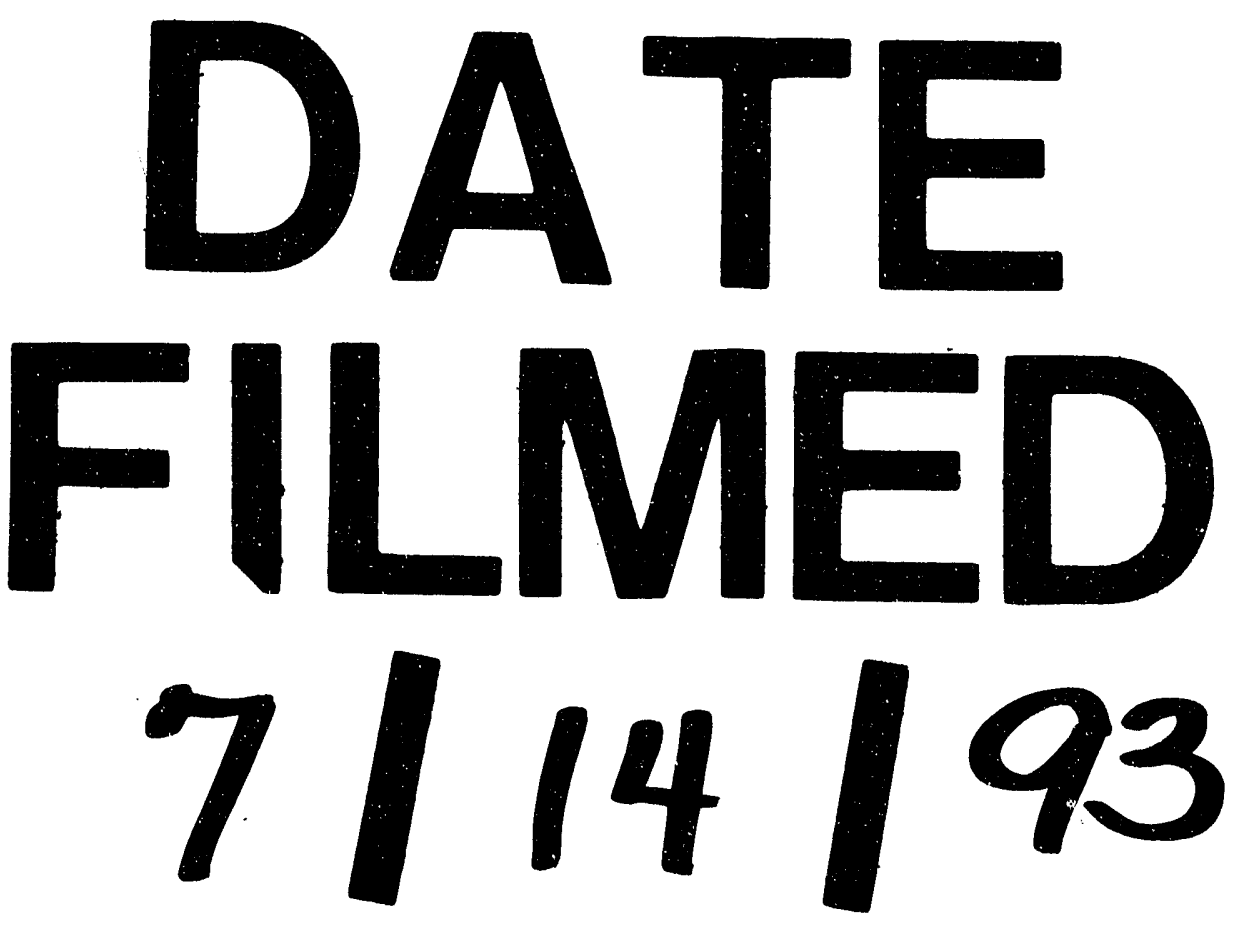


| 